\title{
PERDAS VOLUMÉTRICAS RELATIVAS À COLHEITA FLORESTAL E SEUS REFLEXOS ECONÔMICOS
}

\author{
VOLUMETRIC LOSSES RELATED TO THE FOREST HARVEST AND ITS ECONOMIC \\ REPERCUSSIONS \\ Edson Luis Serpe 1 , Afonso Figueiredo Filho ${ }^{2}$, Julio Eduardo Arce ${ }^{3}$ \\ ${ }^{1}$ LWARCEL, Lençóis Paulista, São Paulo, Brasil-serpe.edson@gmail.com \\ ${ }^{2}$ Universidade Estadual do Centro Oeste, Irati, Paraná, Brasil - afigfilho@gmail.com \\ ${ }_{3}^{3}$ Universidade Federal do Paraná, Curitiba, Paraná, Brasil - jarce@ufpr.br
}

RESUMO

\begin{abstract}
As perdas volumétricas relativas à colheita florestal e seus reflexos econômicos, apresentam grande interesse as empresas florestais. $\mathrm{O}$ objetivo do trabalho foi determinar percentuais de perdas na colheita florestal, os quais podem contribuir para a maior assertividade na valoração de ativos florestais. Foram utilizadas 100 árvores-amostra, selecionadas de acordo com a distribuição de frequência por classe diamétrica em um censo florestal. O número de árvores por classe diamétrica foi definida proporcionalmente a frequência encontrada. As perdas volumétricas quantificadas na colheita florestal, foram: resíduo, toco conforme, serragem de derrubada, serragem de processamento, toco não conforme e quebra de fuste. As perdas volumétricas e econômicas foram divididas em perdas inerentes ao processo e perdas de colheita florestal. As perdas volumétricas foram de $11,92 \%$ e as perdas econômicas representam $\mathrm{R} \$ 330,85$ ha $^{-1}$. A perda econômica do volume retido no toco acima do padrão, foi de $\mathrm{R} \$$ $30,60 . \mathrm{ha}^{-1}$ e a perda por quebra de fuste foi de $\mathrm{R} \$ 300,25 . \mathrm{ha}^{-1}$.
\end{abstract}

PALAVRAS-CHAVE: Não Conformidade, Pinus, Qualidade, Sortimento.

\section{ABSTRACT}

The volumetric losses related to the forest harvest and its economic repercussions are of great interest to forestry companies. The objective of this study was to determine percentages of forest harvest losses, which may contribute to greater assertiveness in the valuation of forest assets. We used 100 sample trees, selected according to the frequency distribution by diameter class in a forest census. The number of trees per diameter class was defined proportionally to the frequency found. The quantified volumetric losses in the forest harvest were: residue, stump, sawdust, processing sawdust, non - conformed stump and stem breakage. The volumetric and economic losses were divided in losses inherent to the process and loss of forest harvest. Volumetric losses were $11.92 \%$ and economic losses represented $\mathrm{R} \$ 330.85$ ha $^{-1}$. The economic loss of the volume retained on the stump above the standard was $\mathrm{R} \$ 30.60 . \mathrm{ha}^{-1}$ and the loss due to a boom broke was $\mathrm{R} \$ 300.25 \mathrm{ha}^{-1}$.

KEY WORDS: Non Conformity, Pinus, Quality, Assortment. 


\section{INTRODUÇÃO}

A atividade florestal possui respeitável papel na economia brasileira, estando inseridas neste ramo, empresas de processamento de madeira (celulose e papel, painéis de madeira reconstituída, siderurgia à carvão vegetal e industrial madeireiro (laminação e madeira serrada) e TIMOs (Timberland Investment Management Organizations, investidores internacionais e nacionais) e reflorestadoras (IBÁ, 2017).

Para a tomada de decisão no setor florestal, além das informações quantitativas e qualitativas, um fato muitas vezes ignorado são as perdas ocasionadas pela atividade da colheita florestal, podendo ser maiores ou menores dependendo da qualidade do povoamento e das operações relacionadas a colheita florestal.

Os desperdícios ocorridos durante a colheita florestal, promovem a necessidade de se realizar avaliações para determinação dessas perdas em volumétricas e econômicas, de forma a subsidiar a tomada de decisão das empresas. As perdas ocorrem em função de falhas dentro do processo produtivo, e essas falhas têm relação com os investimentos que a empresa faz em qualidade, quer seja na prevenção ou avaliação (JACOVINE et al., 1999).

Pelo fato das árvores estarem ainda em pé, não são conhecidas todas as perdas de madeira na colheita florestal. Dificilmente o volume de madeira estimado pelo inventário florestal serão atingidos, devido as árvores terem sido derrubadas e traçadas incorrendo em perdas de colheita florestal (FOELKEL, 2015).

$O$ volume de perdas na colheita florestal é a diferença entre o volume potencial a ser retirado em um sistema de colheita "ideal" e o real volume retirado. O volume potencial é definido como o volume real retirado no talhão, somado ao volume perdido nas seguintes categorias: cepa acima da altura especificada, quebra do fuste e destopo devido ao corte fora do padrão. Os desperdícios podem estar associados ao corte, arraste e operações nos pátios (BARRETO et al., 1998).

A madeira perdida na colheita florestal pode estar na forma de: tocos altos, ponteiros de fuste abaixo de um dado diâmetro pré-estabelecido, toras perdidas, esquecidas ou largadas indevidamente no campo e serragem gerada na derrubada da árvore e secionamento das toras (FOELKEL, 2007).

Um dos grandes desafios da colheita florestal, é fazer com as cepas fiquem o mais próximo do solo, principalmente devido a base da árvore ser a mais grossa, e, consequentemente a mais valiosa, gerando perdas financeiras consideráveis (FOELKEL, 2014).
O volume de madeira deixado no campo durante a etapa de colheita representa um problema operacional. Desta forma, tornou-se imprescindível o conhecimento detalhado de cada etapa da colheita florestal, sua eficiência, rendimento e de suas perdas operacionais (FINK et al., 2008). Sendo assim, o objetivo deste trabalho foi analisar as perdas relativas à colheita florestal e avaliar seus reflexos econômicos.

\section{MATERIAL E MÉTODOS}

\section{Localização da Área de Estudo}

A área de estudo localiza-se no município de Bituruna, região sul do estado do Paraná, nas coordenadas UTM (Universal Transversa de Mercator) 431.383,731 m E e 7.104.262,170 m N (Datum Sirgas 2000, Zona 22J), em uma altitude média de 1.216 m.s.n.m.

\section{Coleta dos Dados}

Os dados foram coletados em plantio misto de Pinus elliottii Engelm e Pinus taeda L. implantado em relevo suave ondulado com área de 43,579 ha, com espaçamento de $3 \mathrm{~m} \times 3 \mathrm{~m}$ (1.111 árvores.ha-1 ${ }^{-1}$.

O povoamento foi conduzido com manejo clearwood, sendo realizado o primeiro desbaste seletivo baixo ( 9 anos de idade, remanescendo 667 árvores.ha-1 ${ }^{-1}$ ), o segundo desbaste seletivo baixo (12 anos de idade, remanescendo 440 árvores.ha-1 ${ }^{-1}$ e o corte raso (16 anos de idade), bem como podas até $6 \mathrm{~m}$ de altura.

Nesta pesquisa, foi realizado o censo florestal, tendo sido mensurados o diâmetro a 1,3 m do solo (DAP), com a utilização de uma suta, e a altura total com o hipsômetro Vertex, de todas as árvores.

\section{Determinação das Perdas na Colheita Florestal}

Comumente, nos inventários florestais visando à estimativa de volumes comerciais, são considerados como perdas em volume: a altura do toco e o volume de madeira abaixo do diâmetro mínimo de aproveitamento (resíduo).

No entanto, durante a colheita florestal, além dessas perdas, existem aquelas causadas pelo traçamento das toras (serragem), perdas pelo destopamento da base da árvore, perdas no volume e número de toras devido à quebra do fuste.

Com os dados do censo florestal, foram selecionadas e derrubadas 100 árvores-amostra, conforme a distribuição de frequência por classe diamétrica encontrada. 
A colheita florestal foi realizada de forma mecanizada, utilizando o sistema de árvores inteiras (Full tree). As árvores foram derrubadas utilizando-se de escavadeira hidráulica de esteira equipada com cabeçote Feller direcional com corrente de passo $3 / 4$ " (espessura do filete de serragem de $1,5 \mathrm{~cm}$ ).

Logo após o corte, foi realizada a medição da altura do toco com trena retrátil. Antes do traçamento "seccionamento" dos fustes em toras, foi realizada a cubagem, com a medição dos diâmetros ao longo do fuste de acordo com os sortimentos comercializados pela empresa. Além disto, foram medidos durante a cubagem, os diâmetros e comprimentos de todas as perdas ocasionadas pela colheita florestal (Tabela 1).

Tabela 1. Perdas volumétricas na colheita florestal

\begin{tabular}{|c|c|}
\hline \multicolumn{2}{|c|}{ Perdas volumétricas } \\
\hline Resíduo* & $\begin{array}{l}\text { Volume de madeira abaixo de } 8 \\
\qquad \mathrm{~cm} \text { de diâmetro }\end{array}$ \\
\hline Toco conforme* & Altura máxima de $10 \mathrm{~cm}$ \\
\hline $\begin{array}{l}\text { Serragem de } \\
\text { derrubada* }\end{array}$ & Espessura de 1,5 cm \\
\hline $\begin{array}{l}\text { Serragem de } \\
\text { processamento* }\end{array}$ & Espessura de 1,0 cm \\
\hline Toco não conforme** & Altura acima de $10 \mathrm{~cm}$ \\
\hline Quebra do fuste** & $\begin{array}{l}\text { Quebra do fuste na derrubada, } \\
\text { arraste ou formação do } \\
\text { estaleiro }\end{array}$ \\
\hline
\end{tabular}

A mensuração do volume das perdas volumétricas na colheita florestal, foi realizada conforme:

1. Resíduo: medindo-se o diâmetro com suta após o diâmetro mínimo com casca de $8 \mathrm{~cm}$ de metro em metro até a altura total da árvore, sendo o volume rigoroso calculado pela fórmula de Smalian e a última seção até a altura total pela fórmula do cone.

2. Toco conforme: mensurado considerando-o como um cilindro, com base no diâmetro à 0,1 $\mathrm{m}$.

3. Serragem de derrubada: mensurado logo após a altura do toco, sendo utilizada a fórmula do cilindro considerando o diâmetro do toco e a espessura de 1,5 $\mathrm{cm}$ (espessura do dente da corrente).

4. Serragem de processamento: mensurado logo após a medição do comprimento da tora, considerando o diâmetro da tora na ponta fina e a espessura de $1,0 \mathrm{~cm}$ (espessura do dente da corrente) sendo esses volumes calculados pela fórmula do cilindro.

5. Toco não conforme: mensurado considerando-o como um cilindro, com base no diâmetro e altura medida, além do diâmetro à $0,1 \mathrm{~m}$.
6. Quebra de fuste: volume estimado pela fórmula de Smalian, considerando o diâmetro e comprimento de um em um metro.

O volume total foi determinado, somando-se o volume dos sortimentos e das perdas, sendo posteriormente separado o volume dos sortimentos e diferentes perdas.

Os volumes individuais dos sortimentos e perdas, foram transformados em percentual e, posteriormente, aplicados ponderadamente de acordo com o diâmetro no volume por hectare determinado no censo florestal, tendo-se, portanto, todos os volumes calculados ao longo do tronco expressos por hectare.

\section{Perdas Econômicas na Colheita Florestal}

Para análise das perdas econômicas resultante da colheita florestal, foi realizada a valoração dos sortimentos por classes de diâmetro, considerando o volume comercial e volume das perdas na colheita florestal, sendo o volume multiplicado pelos preços de madeira praticados pela empresa na região de União da Vitória, estado do Paraná (Tabela 2).

Tabela 2. Preço de toras praticados na região de União da Vitória, estado do Paraná

\begin{tabular}{ccc}
\hline Classe & Classe de diâmetro $(\mathbf{c m})$ & $\mathbf{R} \mathbf{\$} / \mathbf{m}^{\mathbf{3}}$ \\
\hline Serraria 1* & $\geq 23$ & 122,40 \\
Serraria 2 $^{*}$ & $\geq 16$ & 73,69 \\
Celulose $^{*}$ & $\geq 8$ & 32,53 \\
\hline
\end{tabular}

\section{RESULTADOS E DISCUSSÃO}

\section{Perdas Volumétricas na Colheita Florestal}

O percentual de perdas volumétricas geradas pela colheita florestal, sobre o volume comercial com casca é impactado diretamente pelo volume de madeira abaixo do aproveitável (resíduo), quebra do fuste em decorrência dos impactos da árvore no solo na derrubada e arraste até o local de processamento. As perdas volumétricas na colheita florestal somaram 11,92\% (Tabela 3).

Constatou-se que o volume de resíduo possível de aproveitamento após a colheita florestal foi de 9,98\% considerando o volume previsto de madeira abaixo do sortimento $(6,52 \%)$ e o volume de perdas operacionais $(3,46 \%)$. 
Tabela 3. Percentual de volume comercial e perdas volumétricas na colheita florestal

\begin{tabular}{|c|c|c|c|c|}
\hline Volume & Classe & $\mathrm{m}^{3} \cdot \mathrm{ha}^{-1}$ & $\%$ & $\begin{array}{c}\% \% \\
\text { Acumulado } \\
\end{array}$ \\
\hline \multirow{3}{*}{ Comercial } & Serraria 1 & 142,64 & 53,52 & \multirow{3}{*}{88,08} \\
\hline & Serraria 2 & 79,03 & 29,65 & \\
\hline & Celulose & 13,07 & 4,90 & \\
\hline \multirow{4}{*}{$\begin{array}{c}\text { Perdas } \\
\text { inerentes } \\
\text { ao processo }\end{array}$} & Resíduo & 17,37 & 6,52 & \multirow{4}{*}{8,37} \\
\hline & Toco conforme & 3,59 & 1,35 & \\
\hline & $\begin{array}{l}\text { Serragem de } \\
\text { derrubada }\end{array}$ & 0,50 & 0,19 & \\
\hline & $\begin{array}{c}\text { Serragem de } \\
\text { processamento }\end{array}$ & 0,84 & 0,32 & \\
\hline \multirow{2}{*}{$\begin{array}{c}\text { Perdas de } \\
\text { colheita } \\
\text { florestal }\end{array}$} & $\begin{array}{l}\text { Toco não } \\
\text { conforme }\end{array}$ & 0,25 & 0,09 & \multirow[t]{2}{*}{3,55} \\
\hline & Quebra de fuste & 9,23 & 3,46 & \\
\hline Total & & 266,52 & 100,00 & 100,00 \\
\hline
\end{tabular}

Verificou-se que o volume de madeira não passível de aproveitamento (toco) foi de $1,35 \%$ do volume total. 0 volume de toco acima do padrão foi de $0,25 \mathrm{~m}^{3} \cdot \mathrm{ha}^{-1}$, onde $41,8 \%$ das cepas estavam com altura fora da especificação (maior que $10 \mathrm{~cm}$ ).

$\mathrm{Na}$ Tabela 4 apresenta-se a quantidade de madeira retida nas cepas, acima do máximo recomendado e o percentual de cepas que estiveram com altura fora da especificação.

Tabela 4. Volume de madeira retido nas cepas e percentual fora da especificação

\begin{tabular}{|c|c|c|c|}
\hline Autor & $\begin{array}{c}\mathrm{m}^{3} \cdot \mathrm{ha}^{-1} \\
\text { retido } \\
\text { nas cepas }\end{array}$ & $\begin{array}{c}\text { Fora da } \\
\text { especificação } \\
(\%)\end{array}$ & Máquina \\
\hline Atual pesquisa & 0,25 & 41,8 & $\begin{array}{c}\text { Feller } \\
\text { direcional }\end{array}$ \\
\hline $\begin{array}{c}\text { Jacovine et al. } \\
\text { (1999) }\end{array}$ & 1,09 & & Motosserra \\
\hline $\begin{array}{l}\text { Jacovine et al. } \\
\text { (2005) }\end{array}$ & & 58,8 & Harvester \\
\hline $\begin{array}{l}\text { Jacovine et al. } \\
\text { (2005) }\end{array}$ & & 13,0 & Slingshot \\
\hline $\begin{array}{c}\text { Jacovine et al. } \\
\text { (2005) }\end{array}$ & & 21,2 & Motosserra \\
\hline $\begin{array}{c}\text { Fink et al. } \\
\text { (2008) }\end{array}$ & 0,07 & & Motosserra \\
\hline $\begin{array}{l}\text { Pereira et al. } \\
\text { (2012) }\end{array}$ & 2,43 & 30,0 & Motosserra \\
\hline $\begin{array}{l}\text { Fiedler et al. } \\
\qquad(2013)\end{array}$ & $\begin{array}{c}0,21 \mathrm{a} \\
0,30\end{array}$ & & Motosserra \\
\hline $\begin{array}{l}\text { Stroher et al. } \\
\qquad(2014)\end{array}$ & 0,30 & 57,7 & $\begin{array}{c}\text { Feller } \\
\text { buncher }\end{array}$ \\
\hline $\begin{array}{l}\text { Stroher et al. } \\
\qquad(2014)\end{array}$ & 1,45 & 42,9 & Harvester \\
\hline $\begin{array}{l}\text { Luz et al. } \\
\text { (2016) }\end{array}$ & 1,17 & 53,1 & Motosserra \\
\hline
\end{tabular}

Ao comparar a presente pesquisa com colheita mecanizada e a pesquisa de Pereira et al. (2012) com colheita semimecanizada, observou-se que, independente do sistema de colheita florestal, a falta de monitoramento das atividades pode levar a perdas volumétricas e, consequentemente, financeiras para a empresa.

Stroher et al. (2014) constataram que, além das perdas por altura das cepas fora da especificação, o volume perdido das toras em forma de discos da base, foi de 4,79 $\mathrm{m}^{3}$.ha ${ }^{-1}$. Esses autores ainda consideraram o volume de madeira perdido devido à linha de corte do disco do feller buncher, que foi de 4,25 $\mathrm{m}^{3}$.ha-1.

Em pesquisa de mudança no sistema de colheita florestal buscando a redução de perdas de volume de madeira retida nas cepas, foi evidenciado que a altura média das cepas no sistema cut to lenght utilizando harvester é de $15 \mathrm{~cm}$ e com o uso do sistema de colheita full tree utilizando feller buncher reduziu para $10 \mathrm{~cm}$ (VERACEL, 2014).

A literatura pesquisada (Tabela 4), indicou que os volumes de perdas de madeira retido nas cepas pode variar de 0,07 a 2,43 $\mathrm{m}^{3} \cdot \mathrm{ha}^{-1}$, a qual, comparada com a atual pesquisa $\left(0,25 \mathrm{~m}^{3} \cdot \mathrm{ha}^{-1}\right)$, demonstra a necessidade de melhoria na qualidade das atividades de colheita florestal. Observa-se, ainda, a alta frequência de cepas com altura fora da especificação, a qual variou entre $13,0 \%$ e $58,8 \%$ na literatura pesquisada e de $41,8 \%$ na atual pesquisa.

\section{Perdas Econômicas na Colheita Florestal}

Tendo-se determinado as perdas volumétricas na atividade de colheita florestal, seus efeitos econômicos são apresentados na Tabela 5.

Tabela 5. Efeitos econômicos das perdas na colheita florestal

\begin{tabular}{cccc}
\hline Volume & Volume.ha-1 $^{-1}$ & R\$.ha $^{-1}$ & (\%) \\
\hline Comercial & 234,74 & $23.708,29$ & 98,62 \\
\hline Toco não conforme & 0,25 & 30,60 & 0,13 \\
\hline Quebra de Fuste & 9,23 & 300,25 & 1,25 \\
\hline Total & $\mathbf{2 4 4 , 2 2}$ & $\mathbf{2 4 . 0 3 9 , 1 4}$ & $\mathbf{1 0 0 , 0 0}$ \\
\hline
\end{tabular}

A perda econômica na atividade de colheita foi de $1,38 \%$ e representou $\mathrm{R} \$ 330,85 \cdot \mathrm{ha}^{-1}$. Considerando o volume retido no toco acima do padrão (acima $10 \mathrm{~cm}$ ), a perda econômica foi de $\mathrm{R} \$ 30,60 \mathrm{ha}^{-1}$ e a perda por quebra de fuste foi de $R \$ 300,25 \cdot \mathrm{ha}^{-1}$.

Luz et al. (2016), em análise da perda de rentabilidade 
da madeira remanescente em cepas de Eucalyptus urophylla S.T. Blake, verificaram que a perda econômica foi de $R \$ 43,29 . \mathrm{ha}^{-1}\left(\mathrm{R} \$ 37,00 / \mathrm{m}^{3}\right)$.

Pereira et al. (2012), em avaliação da qualidade do corte florestal com motosserra em Eucalyptus grandis Hill ex Maiden, verificaram perda econômica por hectare de R\$ 172,53 , sendo considerado o preço da madeira de $\mathrm{R} \$$ $70,98 / \mathrm{m}^{3}$.

Em análise da qualidade da colheita florestal de eucalipto em diferentes declividades, Fiedler et al. (2013) constataram que a perda de volume de madeira retido nas cepas proporciona, em termos monetários, valores que variam entre $R \$ 14,92$ e $R \$ 21,82$ por hectare em relação ao valor médio da madeira de $\mathrm{R} \$ 71,89 / \mathrm{m}^{3}$.

Jacovine et al. (1999), no uso de uma metodologia para avaliação dos custos da qualidade na colheita florestal semimecanizada em eucalipto, constataram que a quantidade de madeira retida nas cepas resulta, em termos monetários, perda de $\mathrm{R} \$ \mathbf{7 , 7 8}$ por hectare, considerando o valor da madeira de $\mathrm{R} \$ 7,14 / \mathrm{m}^{3}$.

\section{CONCLUSÕES}

O volume de madeira abaixo do diâmetro limite aproveitável e a quebra de fuste na atividade de derrubada e arraste foram as perdas que acarretaram o maior impacto no volume comercializado.

Ferramentas de gestão da qualidade para análise de defeitos ou não conformidades como diagrama de Ishikawa, diagrama de Pareto, 5W2H, PDCA e 6 Sigma, ferramentas de análise do modo e efeitos de falhas (FMEA) e ferramentas de análise do resultado (FCA), podem ser praticadas buscando a minimização de perdas e melhoria contínua dos processos.

\section{AGRADECIMENTOS}

À Remasa Reflorestadora S.A., pela autorização e apoio no trabalho de campo.

\section{REFERÊNCIAS}

BARRETO, P. et al. Costs and benefits of forest management for timber production in eastern Amazonia. Forest Ecology and Management, v.108, n.1. p.9-26, 1998.

FIEDLER, N.C. et al. Análise da qualidade da colheita florestal de eucalipto em diferentes declividades. Revista Científica Eletrônica de Engenharia Florestal, v.22, n.1, p.1-8, 2013.

FINK, J.L. et al. Caracterização da altura de corte em desbaste de Pinus elliottii com 6 anos, 2008. Disponível em: http://www.unicentro.br/pesquisa/anais/seminario/pesquisa20 08/pdf/artigo_731.doc

FOELKEL, C. Gestão ecoeficiente dos resíduos florestais lenhosos da eucaliptocultura, 2007. Disponível em: http://www.eucalyptus.com.br/capitulos/PT07_residuoslenhoso s.pdf

FOELKEL, C. Medição da madeira na forma de toras empilhadas, $2015 . \quad$ Disponível em: http://www.eucalyptus.com.br/artigos/news48_Toras_Empilha das.pdf

FOELKEL, C. O problema das cepas residuais das florestas plantadas de eucaliptos, 2014. Disponível em: http://www.eucalyptus.com.br/artigos/news45_Cepas_Tocos.p df

IBÁ. Relatório 2017, 2017. Disponível em: http://iba.org/images/shared/Biblioteca/IBA_RelatorioAnual201 6_.pdf

JACOVINE, L.A.G. et al. Avaliação da qualidade operacional em cinco subsistemas de colheita florestal, Árvore, v.29, n.3, p.391400, 2005.

JACOVINE, L.A.G. et al. Descrição de uma metodologia para avaliação dos custos da qualidade na colheita florestal semimecanizada, Ciência Florestal, v.9, n.1, p.143-160, 1999.

KOHLER, S.V. Erros amostrais e não amostrais em inventários de florestas plantadas. 2017. 173p. (Tese de doutorado).

LUZ, D.S. et al. Análise da perda de rentabilidade da madeira remanescente em cepas de Eucalyptus urophylla. In: IV Semana de Engenharia Florestal da Bahia e I Mostra da Pós-Graduação em Ciências Florestais da UESB, 2016, Vitória da Conquista. Anais... Bahia: UESB, 2016.

PEREIRA, D.P. et al. Avaliação da qualidade do corte florestal com motosserra. Cerne, v.18, n.2, p.197-203, 2012.

STROHER, R.R. et al. Avaliação da perda de madeira em dois sistemas de colheita florestal mecanizada. Enciclopédia Biosfera, v.10, n.19, p.238-249, 2014.

VERACEL. Mudança no processo de colheita florestal com interação na silvicultura. In: 3ํㅡㄹ Encontro Brasileiro de Silvicultura, 2014, Campinas. Anais... Curitiba: Embrapa Florestas, 2014. p.4757. 